\title{
THE INTERPERSONAL MEANINGS OF WORDS AND IMAGES IN ADS: AN INTERSEMIOTIC COMPLEMENTARITY VIEW
}

\author{
Fina Khanifa, Khristianto \\ Faculty of Letters, Universitas Muhammadiyah Purwokerto \\ fkhanifa14@gmail.com, khristianto@ump.ac.id
}

\begin{abstract}
This study is to find out the interpersonal meaning and the intersemiotic complementarity in selected public service advertisement of violence against children prevention campaign. The ads were found in social media of Pinterest; they were used in the campaign in June 2014 by Amnesty International. Another ad is from UNICEF which posted in its website in the same periode. Employing Royce's intersemiotic complementarity framework (2001), it analyzed how the visual and verbal signs work together to create common messages sent to the public as viewers/readers. Based on the analysis, it is found out that the five aspects of visual features --visual contact, social distance, involvement, power relation, and modality - have worked together to construct the interpersonal meaning. The close up shot showing the detail of the bruises on the nose emphasizing a high modality; it represents a high naturality. The boy in bruises looks directly at viewers' eyes, demanding a help from them. The equal frame on the picture tells the readers that the boy can be part of every one's life. It may happen in any place and the readers are asked to do take an action. In terms of verbal features, the declarative sentences are used to inform the facts. It is to highlite the clear message in the image, saying that such a violence may be taken by a mother who inherits the boy's nose- the one who actually loves him very much, but the situation has changed her a lot. Both visual and verbal modes contribute to convey interpersonal meaning. The intersemiotic complementarity in the advertisement is realized interpersonally through the meanings projected in both modes through the reinforcement of address.
\end{abstract}

Keywords: interpersonal meaning, ads, multimodality, image, text, complementarity framework

\section{INTRODUCTION}

Advertisements are progressively entering people's daily lives and playing a larger part in their lives. It has a powerful ability to convince and influence people. There are two kinds of ads from their purposes, i.e. commercial and public service ads. The former has an objective to make a profit, as they usually promote products and/or sevices. Meanwhile the latter is made to serve public information-its orientation is for public interest (Shuting Liu, 2019). In the recent pandemics, there are so many public health ads to campaign the practices of health protocols, preventing the spread of the virus.

Public Service Advertisement (PSA) has an important role to deliver message any public issue to the society. PSA will usually relate to educate, and to raise public awareness on certain issues over the publics as the main target audience (Martiniuk et al., 2010). Among issues of public interests, a violence on children obtains a particular priority from the related institutions. The fact has shown that up to 1 billion children aged 2-17 years in the world have experienced physical, sexual, or emotional violences. For this reason, some organizations, like Amnesty International and UNICEF, display PSA for campaign fighting against the cases to deliver the urgent and critical message to the society.

Such ads usually contain two forms of signs, visual and verbal. The visual content is more prominent than the verbal one. Visualization in ads is more effective than words like an old saying that "a picture is worth a thousand words" which is originally coined by Barnard (1921). It means a picture can tell a complete story, and even it may better than a verbal story, as in a Chinese proverb, saying "one picture is worth ten thousand words" (https://www.phrases.org.uk/meanings/a-picture-is-worth-athousand-words.html). Thus, a verbal sign only functions to lock up the intended meaning to lead potentially multi-interpreted pictures.

Thus, visual and verbal elements in such ads need more exploration to access its comprehensive meaning. For this purpose, Royce (2001) has proposed a descriptive framework to analyze multimodal texts, especially those combining words and images. He adopts Halliday's three metafunctions (1994) and visual grammar (Kress and Leeuwen, 1996). Royce concludes that both images and texts in a piece of text tend to work together to evoke a single meaning for the readers/viewers. He refers to this as an intersemiotic complementarity (Royce, 2001). This study will limit its analysis on the interpersonal meaning by exploring the image and the text employed in PSA. 
This research employed a qualitative method. It is applied to explain how the data in the forms of visual and verbal texts are constructed to evoke an interpersonal meaning. The primary data are the digital posters of PSA on violence against children prevention campaign. An ad can be found in two websites of Ads of the world (https://www.adsoftheworld.com/media/print/amnesty_international_nose), while another is no longer displayed. They belong to two international organizations, Amnesty International and UNICEF. The data were taken on February 9, 2021. This applied Royce's intersemiotic complementarity framework (2001), which combine Halliday's SFL (1991) and visual grammar (Kress and Leuween, 1996).

\section{RESULTS AND DISCUSSION}

The description of findings is broken into two sections: interpersonal realization of visual and verbal signs and their complementarity. The first part presents how each sign manifest its interpersonal exchange between the image/text and the viewers/readers, and another part focuses on how the two works on the same line to achieve the same goal.

\section{II.1 Visual Signs}

On the side of visual code, there five aspects identified to have contributed in building an interpersonal interaction between the image and the viewers. Those are visual contact, social distance, involvement, power relation, and modality. Each of them will be addressed, based on the features of the images seen from Kress and Leeuwen's visual grammar theory (2006).

\section{II.1.1Visual contact}

Seen from this aspect, the picture in figure 1 shows a picture of a boy with broken nose. His eyes look directly at ours as viewers. His gaze means that he demands something from us. All of the viewers are encouraged to take an imaginary relation he offers (Kress and Leeuwen, 2006). In other words, the represented participant demands a service; he begs the audience to take some efforts to help him. $\mathrm{He}$ really asks them to release himself from his miserable situation. At a closer look, viewers can see that the bruises are quite new; the violence may occur in one or two days before. An alert comes with the fact, i.e., it may recur today or in near future, unless somebody among the viewers do some real measure to prevent the violence. Thus, the image can be said to be a "demanding picture", which seriously beg the audience to take some urgent actions.

Another picture represents many people in the scene. They are busy doing their own activities. They seem to be preoccupied by the daily work, focusing on making or repairing foot wares. Meanwhile, a lady looks very upset on a little girl, making her ready to kick the girl with her highheeled shoe on. Here, the participants do not look at the viewers. They are displayed as a scene to be observed. They are impersonal and detached from eye-contact with viewers. Compared to the figure 1, it represents the actors, not the victims. The participants are positioned at the third party for the audience and the producer of the image (Kress and Leeuwen, 2006). It informs to the viewers that such incidence can happen and people there easily ignore it. They may take it easy as it is not their business. In fact, they can do something to help the victim in the situation. The viewers is indirectly persuaded not to behave like the people in the picture.

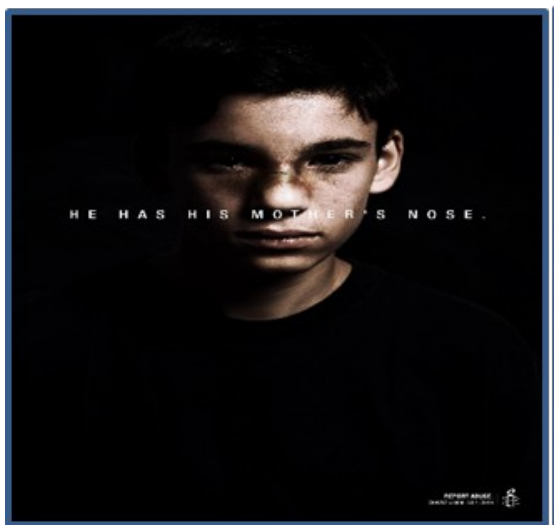

Fig1. Amnesty International's PSA

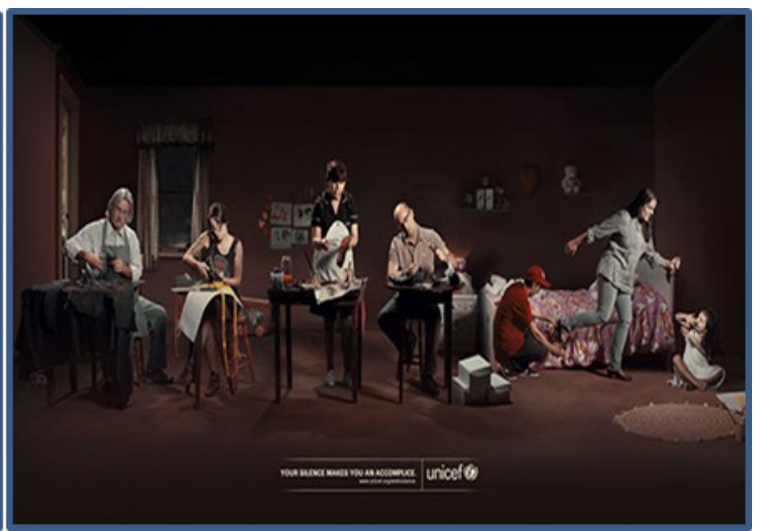

Fig 2. UNICEF's PSA 


\section{II.1.2Social Distance}

The represented participant in figure 1 is shot in a close-up mode (Kress and Leeuwen, 2006), where the head and the shoulders of the subject are visible; this way facilitates the audience to capture detail facial expressions. The audience, then, can understand how the represented is feeling and thinking. The close-up shot is to tell a scary story of the represented participant that make the audience feel something. With this shot, a close personal distance is built up, making an intimate relation between the looked and the on-lookers. The boy in the picture is represented as someone very close; he is not anybody. He becomes a part of the people among the audience. He can be a close neighbor, a friend, and even a family to them. In sum, the image of boy in a close up shot creates a close relation to the viewers.

Meanwhile, figure 2 employs a very long shot on many people working in a complete setting and background, not only the characters. It does not only focus on the people, but also on the background. The shot frames the subject from a distance and focuses on its surroundings but the subject is still noticeable in it. This kind of shot implies a public distance (Kress and Leeuwen, 2006). It also proves no contacts between the audience and the represented individuals, making them to be strangers, as other people. In contrary to the first picture, it establishes a distancing gap from the viewers.

\section{II.1.3Involvement}

Figure 1 adopts a frontal angle to indicate an involvement of the viewers. The viewers and the represented boy are at the same eye line, putting both parties in the same circle. Here the audience is made to look instantly at the subject, implying a strong and clear involvement. Thus, their high degree of involvement with the subject in the image is established (Kress and Leeuwen, 2006).

The represented participants in another image are put at oblique position; the viewers do not share the eye line with any characters there. This way detaches them from all the represented participants and their world. They are people out there, to whom the viewers are not a part. This kind of angle surely creates a feeling of detachment, that the person depicted is of less importance. It has lured a feeling that the viewers should not do what the subjects do.

\section{II.1.4Power Relation}

In both images the represented participants are seen from an eye level angle (Kress and Leeuwen, 2006). This has created a neutral perspective (not superior or inferior). It was taken to convey equality among the subjects in the image and the audiences. There is no power differential between the viewers and the participants depicted. This angel also connects the viewer to the emotions of the portrayed participant on the screen. This functions to imply that the incidences of violence are parts of the social life where every body should anticipate.

\section{II.1.5Modality}

In figure 1 the background has lesser degrees of detail indicating lower modality. The image's background is a black. The colors are not vibrant, and the depth is natural. Dark colors convey a sad and miserable atmosphere. Some of the finest details of the boy was shown in a degree of representing or abstracting detail, and the use of texture, lighting, and tone increases its modality. The image does not use bright colors to emphasize the seriousness of the situation. The image has varied degrees of realism or credibility. The picture creator may be implying to the viewers that the participant's identities is real. Thus, seen from the most salient object, the image has a high level of modality or naturality (Kress and Leeuwen, 2006). It is a real subject who just experienced a severe violence, committed by some adult, supposed to be his own mother, as mentioned in the text.

In figure 2 in terms of contextualization, the background is depicted in great detail, it depicted as being inside an empty house with broken walls, doors and roofs. The image has fully saturated colors. In terms of being real or credible, the visual modality is high (Kress and Leeuwen, 2006). This advertising is honest and trustworthy in presenting reality to the viewers. However, as a real incidence, the scene is surely artificial. It has been hyperbolized to create a strong feeling of people's ignorance on the violence incidence. This is to stimulate an awareness on the audience's mind that any kind of ignorance should not be there. The victim can be easily prevented if we can spare our little care.

\section{II.2 Verbal Signs}

In analysis verbal interpersonal features, the clause as exchange and the range of choice provided in the Mood and Modality (Halliday, 1994). Based on the finding the analysis of mood system in Public 
Service Advertisement of selected violence against children prevention campaign from Amnesty International and UNICEF, the clauses used in figure 1 and 2 are declarative sentence.

\begin{tabular}{|c|c|c|}
\hline $\mathrm{He}$ & has & his mother's nose \\
\hline $\mathrm{S}$ & $\mathrm{F} / \mathrm{P}$ & $\mathrm{C}$ \\
\hline MOOD & & \\
\hline
\end{tabular}

\begin{tabular}{|l|l|l|l|}
\hline Your salience & makes & you & an accomplice \\
\hline S & F/P & C & C \\
\hline MOOD & \multicolumn{2}{|l|}{ Residue } \\
\hline MOOD & & \\
\hline
\end{tabular}

\begin{tabular}{|l|l|}
\hline Report & abuse \\
\hline P & C \\
\hline Residue & \\
\hline
\end{tabular}

Table 1. Declarative Mood and Imperative Mood in the Ads

This table shows that the clause is a statement, as realized by their declarative mood system, subject comes before finite. In the declarative mood, a sentence actually offers a statement of fact about things that people have really experienced (Halliday, 1994). As it is also proved in another study (Faidah, 2018) that the statement deals with giving information. Here the text maker provides information to the reader about the implications of child abuse and person's attitude if they are unconcerned about the problem.

The use of pronoun is also found in the clauses such as "he", "his", "you" and "your". The third person pronouns "he" and "his" tell the viewers that the participant is not the author, but someone else. Second person pronouns "you" and "your" are a face-to-face way of establishing friendly relationships and shortening the distance between the speaker and the readers. There is the imperative sentence found in the advertisement such as: Report abuse. The use imperative is commonly used in advertisement to persuade readers to take certain actions or to a 'call for action' to stop the abuse. In the lower part of the ad, logo and website of the institution also listed for identification of organization, which clearly shows that the advertisement is from a reliable source.

In terms of modality, there is no usage of modal among the clauses there. This means that the propositions are facts with an absolute truth. Modality is used to portray the judgements and attitudes toward the messages they communicate (Halliday, 1994). There is no argument about the probability or frequency of a proposition, and any comments that may also be made in the clauses. All of the clauses in the commercial are mostly statements, which are declarative sentences that provide information.

Yet, with images the propositions do not only inform the facts, but provoke more on the audience' minds to do something. "He has his mothers' nose", with nose image broken down has brought up a feeling of deep concern and anxiety that it should not happen again. "Your silence makes you accomplice" are threatening the readers with a prison, saying that people who remain silent, as they see a violence, can be sued in the court. Besides, the image of an excessive ignorance among the people has made the viewers to detach from.

Thus, it has been shown here that images and texts can be analyzed at once and result in more comprehensive meaning than an individual analysis of each. Discussing the intersemiotic complementarity in the interpersonal meaning of the advertisement, the study found out that both advertisements show an intersemiotic Reinforcement of Address. It shows Athat the maker addresses their readers by making statement. Reinforcement of address is an identical form of address where visual 
and verbal modes, utilizing the methods inherent in their modes, ask questions or make statements in the exchange of information (Royce, 1999). In our case, each ad here informs an information to persuade and to elicit some urgent and critical measures to prevent the incidences of violence among the children in the world. This demanding function is obviously seen from the emergence of imperative mood, asking the readers to do an action of reporting "the abuse" over the children.

High modality with their naturalities in the represented participants in the images functions to represent that violence incidences are true facts. This is in line with the selection of declarative propositions in the main clause in each ad. The factuality of the information in the clauses are emphasized more by the absence of modal operator or any kinds of modality meaning realization in them. Here this presents a clear and strong message that the depictions are really true. The congruent realization of command in an imperative mood supports this tendency of the high modality or high naturality in the images.

Though the ads belong to different organizations. They seem to complement each other. The first emphasizes the information from the victim perspective, by presenting the boy in a close up shot, showing details of the bruises on his nose. His gaze surely elicits a strong feeling of sadness on the viewers. With the anchor of the clause, “...his mothers' nose”, the ad successfully touches every viewer's deep feeling. Meanwhile the second puts the same issue from the perpetrators, seen as third parties. A clause quotes the idea from the law and it makes a real threat for any ignorance over the child abuse. This creates a demanding proposal, promising something negative toward the readers. The picture positions the viewers detached from the represented participants, depicted to have an excessive ignorance, like the people who have lost their humanity. This puts on the audience a feeling of anger on such a behavior - making them aware that the negation over the violence will obviously increase many more victims. Thus, both ads have done their functions well in the public minds.

\section{CONCLUSION}

The images are generally of high modality to ensure that the depictions are true and reliable. The high modality has been proved in terms of contextualization, representation, illumination, and color saturation with detailed environment description and well-made background setting. High-modality images are more genuine and can make a stronger impact on viewers, thus increasing the possibility of influencing viewers' behaviors. In verbal interpersonal features, declarative sentence is used in the advertisements' verbal text. The clauses used in the advertisements are mostly declarative, informing the readers about the impact of child abuse and the attitude of those who are apathetic about the issue. The intersemiotic complementarity is realized interpersonally through the meanings projected in both modes through the reinforcement of address. The high naturality of the images and the use of declarative without any modality meaning function to highlight the truthful representation about the violence. The dramatic representation in the images also touches the feeling of audience and moves them to take actions, which are mentioned clearly in the imperative mood applied in one of the ads, urging them to do something very important.

\section{REFERENCES}

Cook, G. 1992. The discourse of advertising. London: Routledge.

Creswell, John W. 2003. Research Design: Qualitative, Quantitative, and Mixed Methods Approaches (2nd ed). California: Sage Publications.

Faidah, C.L. (2018). Mood Analysis on Spoken Texts of Teacher's Scaffolding Talks in English Subject. Semarang: Walisongo State Islamic University.

Halliday, M.A.K. 1994. An Introduction to Functional Grammar. 2ed. London: Edward Arnold.

Kress, G and Van Leeuwen, T.1996. Reading Images. London and NewYork: Routledge. . 2006. Reading Images: The Grammar of Visual Design. Second Edition London: Routledge.

Liu, Shuting. 2019. A Multimodal Analysis of the Interactive Meaning in Public Service Advertisement. Journal of Advance in Linguistic, Vol 10.

Martiniuk, A.L., Secco, M., Yake, L., \& Speechley, K. N. 2010. Evaluating the Effect of a Television Public Service Announcement About Epilepsy. Health Education Research, 25(6), 1050-1060.

Royce, Terry. D. 1999. Visual-Verbal Intersemiotic Complementarity in The Economist Magazine. The University of Reading, England. 
2001. Intersemiotic Complementarity: A Framework for Multimodal Discourse Analysis. Teachers College, Columbia University. 
